Journal of Social Sciences 8 (2): 263-266, 2012

ISSN 1549-3652

(C) 2012 Science Publications

\title{
Survival and Change of Mahoree Tradition in Cambodian Society
}

\author{
Pittayawat Pantasri, \\ Jarernchai Chonpairot and Boonsom Yodmalee \\ College of Music, Mahasarakham University, Tambon Kamrieng, \\ Amphur Kantarawichai, Maha Sarakaham, 44150, Thailand
}

\begin{abstract}
Problem statement: Mahoree, is an important music ensemble in Cambodia since the Angkorean period. Mahoree formerly belonged to the court or noble Cambodian families. Mahoree is very popular and practiced by ordinary people and plays an important role in Cambodian society. Mahoree is a culture of the community and the Cambodian society and can be preserved and promoted by community participation. Approach: This research was a qualitative research study. The research data was derived from document analysis and field research carried out between June, 2009-July, 2011. The instrument used included a basic survey forms, observations forms, interviews forms and focus-group discussions. The sampling group was made up of 27 key informants, 22 casual informants and 18 general informants. The research area includes Phnom Penh, Battambang province and Siem Reab province. This research aimed to 1 . To study factors that affects the survival and changes of Mahoree ensemble in Cambodian society 2. To create guidelines for the conservation and promotion of Mahoree ensembles in Cambodia. Results: The changes affecting Mahoree come from internal and external influences of modern Cambodian society. External influence contributed significantly to the changes of Mahoree in Cambodian Society, such as modifying the playing methods, change of clothes, use of instruments from different cultures to mix and make the performance more appealing to modern audiences. The promotion and encouragement of Mahoree music instruments can be done by increasing the centers for learning Mahoree songs, learning about Mahoree music, the nature of the Mahoree music, the type of Mahoree music, the benefits of Mahoree, the song used in the rituals that require Mahoree and intellectual property rights and care for Mahoree artists. Encourage the singing of the Mahoree in music ensembles, promoting new songs, publishing Mahoree music with modern recording and musical notes, distribution of the songs, inspect and maintain the intellectual property rights of artists. Create a variety of teaching formats, promotion of youth music in various locations, promotion of learning Mahoree in state organizations and create Mahoree manual for teachers. Promote the importance of Mahoree instruments and production and distribution of teaching materials in various formats and encourage visitors to seek out knowledge about music. Conclusion: Factors that affected the survival and change of Mahoree ensemble in Cambodian society were learning and inherited of Mahoree culture from the past to the present and the signifying of the role of Mahoree in Cambodia. The guidelines for conservation and promotion or encouragement of Mahoree can be carried out in as many aspects as possible through community participation and by cooperation of government, private sectors and communities.
\end{abstract}

Key words: Conservation, survival, change, mahoree, cambodian, music, cambodia

\section{INTRODUCTION}

Mahoree, is an important music ensemble in Cambodia since the Angkorean period. Formerly the Mahoree belonged to the court or noble Cambodian families. Mahoree is currently popular and practiced by ordinary people and plays an important role in
Cambodian society. It is used with folk dance s, banquets, weddings and home opening ceremonies. This qualitative research aimed 1. To study factors that affects the survival and changes of Mahoree ensemble in Cambodian society 2. To create guidelines for the conservation and promotion of Mahoree ensembles in Cambodia.

Corresponding Author: Pittayawat Pantasri, College of Music, Mahasarakham University, Tambon Kamrieng, Amphur Kantarawichai, Maha Sarakaham, 44150, Thailand 


\section{J. Social Sci., 8 (2): 263-266, 2012}

\section{MATERIALS AND METHODS}

This research is a qualitative research study. The research data were derived from document analysis and field research carried out between June, 2009-July, 2011. The instrument used included a basic survey forms, observations forms, interviews forms and focusgroup discussions. The sampling group was made up of 27 key informants, 22 casual informants and 18 general informants. The research area includes Phnom Penh, Battambang province and Siem Reab province.

\section{RESULTS}

Survival and Changes to Mahoree in Cambodian Society: Survival of the learning and inheritance of learning cultural heritage with the inherited traditions of Mahoree occurred in Cambodian Society through learning and acculturation of Mahoree in all aspects. Instruments, traditions, learning process are occurring mostly in the family or communities. Former professional musicians inherited from family members and living community members. Traditions and institutions should continue to support each other by the participation of the society to cooperate and work together to create social stability by cultivating a love of music to children and youth; inherit knowledge by using the process of "Muk Patha" (Oral Tradition). This is consistent with Phimphon Chaichitsakun (2002) in which the cultivation of Thai music for children and youth is building a good relationship between teacher and pupil. It is also consistent with Korakot Wongsuwan (2006) in which the inheritance of knowledge of Thai Music from indigenous philosophers is performed by applying the traditional teaching method of "Muk Patha" (Oral Tradition) which is coupled with demonstration, practice and live performances.

Mahoree is currently very popular with the general public and performs the role of music for a celebrations and special social events. But the requirements and opportunity for Mahoree is in ceremonies and festivities associated with Buddhism, weddings or other religious events and rites, representing the structure of social relations with the Buddhist temple-centered relationships in the community, consistent with Sansani Chasuwan (2006) in the relationship of the three institutions of Buddhist temple, community and home. The opportunity to perform Mahoree in Cambodian Society is still minimal compared to other types of modern musical performances in Cambodia but demonstrates the increasing importance of the cultural entertainment of Mahoree of the Cambodian people and gaining popularity even through economic and social problems within the country and the impact of the war in the past. This is consistent with Phongphon (2008) which studied the music of Lao People's Democratic Republic, in which music is mostly performed for entertainment because most people are occupied with their occupation and providing income for their families. The modern economic situation has resulted in the lack of sponsors to support musicians. But the opportunity for Mahoree in Cambodian Society is in the necessity of Mahoree's role to meet the psychological needs and accompany rituals and important social events.

Guidelines for conservation and Encouragement of Mahoree in Cambodia: The conservation Mahoree instrument can be achieved through the preparation and creation of a musical instrument museum in Cambodia within the community through public or private organizations and preservation of instruments in its current form to demonstrate the instrument's history and development of Cambodia. To take action, maintenance and public support for the organization. Include Mahoree in the community's learning center. Committee support of cultural centers in the provinces. Catalog of instrument production craftsmen in the community to prepare a database and knowledge of production and repair of musical instruments. This can be done in Phnom Penh, Battambang province and the province of Siem Reap. These factors are vital to the conservation of arts and culture and is consistent with Chonpairot (2008) which suggested the conservation, rehabilitation and development of ethnic identity and traditions of Kula in the Northeast, in which the success of conservation of cultural identity and the establishment of the museum will enhance the value of their identity and traditions of the community.

\section{DISCUSSION}

The changes affecting Mahoree come from internal and external influences of modern Cambodian society. External influence contributed significantly to the changes of Mahoree in Cambodian Society, such as modifying the playing methods, change of clothes, use of instruments from different cultures to mix and make the performance more appealing to modern audiences which have changed the inheritance and lifestyle development of music. This is consistent with Zainal et al. (2009) where the indigenous music and instrument of "Anklung" has had a long history of adapting to social and community needs which started from being an instrument to accompany festivals, children's toys, used in festivities to arouse the soldier's fighting spirit, used by beggars to attract passers by and is currently a very popular folk music instrument in Malaysia. The 


\section{J. Social Sci., 8 (2): 263-266, 2012}

process of change and adaptation has been occurring since historic times through the interaction of the cultural exchange between Cambodian communities and other communities and countries. This is the acceptance of different cultures which reduces cultural conflict, consistent with Sisantisuk (2001). The changes arising from external influences affects mostly material culture such as including carbonated drinks as materials for the Wai Kru ritual (Commemorate and Honor Teachers) which was accepted because it was easier to find and use. The non-material culture such as beliefs, traditions and ceremonies in Cambodian Society will continue to adhere to traditions and original faith. This is consistent with Ueasaman and Changes (1994) in which the spread of urban culture into the rural society made little changes to rural societies, traditions and rituals related to life and health which are still practiced with minimal changes from the past.

The promotion and encouragement of Mahoree music instruments can be done by increasing the centers for learning Mahoree songs, learning about Mahoree music, the nature of the Mahoree music, the type of Mahoree music, the benefits of Mahoree, the song used in the rituals that require Mahoree and intellectual property rights and care for Mahoree artists. Encourage the singing of the Mahoree in music ensembles, promoting new songs, publishing Mahoree music with modern recording and musical notes, distribution of the songs, inspect and maintain the intellectual property rights of artists. Create a variety of teaching formats, promotion of youth music in various locations, promotion of learning Mahoree in state organizations and create Mahoree manual for teachers. Promote the importance of Mahoree instruments and production and distribution of teaching materials in various formats and encourage visitors to seek out knowledge about music. This is consistent with Kuntan (1957) in promoting music to flourish requires four key factors. (1) to investigate the formation and fundamentals, (2) Preservation of the traditional elements by making minimal modifications to the art which must be compatible and preserve the value and cultural value of tradition and blending it with modern elements for promotion and sustainability, (3) To promote and extend the music and performance so that it is widespread and popular among the modern community and audiences. (4) Update and modify to suit the immediate environment and current events.

Mahoree is a culture of the community and the Cambodian society should preserve and promote Mahoree by community participation. The ultimate goal is to create a society with strong cultural and sustainable development. This approach will build up to the development of Cambodian society by the culture of the community. The link between economic and cultural communities is consistent with Wasi (1994) in which the integration of knowledge in all aspects of cultural and economic links with the community. So that the culture of the community survives with the community and create a sustainable distribution of income and strengthen the economy.

\section{CONCLUSION}

The guidelines for conservation and promotion or encouragement of Mahoree should be carried out as many aspects as possible by cooperation of government, private sectors and communities. It was hoped. That the results of this study should be applied for creative cooperation of concerned parties, conservation, promotion, and development of Mahoree ensembles. Each community could establish cultural identity and use it for economic development, create their own pride and dignity, and maintain their way of life sustainably. Cambodian society should protect, promote and develop all aspects of culture in the community. The collaboration between government agencies, NGOs and communities is to engage the culture of the community and managed by community participation. The community and the learning process is the heart of sustainable development.

\section{Suggestions and recommendations:}

Suggestions for application: Community leaders should be aware of the importance of the traditions of the community. The research result is a good model for the conservation and promotion of local culture, nurture a sense of dignity, respect and to provide community members so that everyone sees the advantages and benefits of the good things in the community as well as creating harmony and a cherished local heritage.

School should be aware of the importance of local customs and traditions of the people and centered on the promotion of local culture, research and prepare students to teach in local schools at all levels with emphasis on culture to instill values, to love the local cultural heritage, creating a sense of community pride in creating harmony and cherished local heritage.

Should support research in local culture and lifestyle of ethnic groups in each locality to strengthen the community in various fields of both economic and spiritual stability and unity of the nation. Because each ethnic group has a unique and rich heritage of their ancestors and is diverse which will create the extension of knowledge and cultural exchange.

NGOs should be working on the conservation culture. This research can serve as a guideline and how to apply conservation efforts in the development and promotion. Youths or the general public can apply it to 
the professional occupations and will provide career enhancement, quality way of life and better living.

Provincial Cultural Office should apply this research to find ways to preserve and promote the traditions of local communities, culture and tradition in the community and intellectual property rights of indigenous philosopher's in order to develop a systematic and fair benefits for indigenous philosopher.

Provincial organization and administrations should utilize this research on how to deploy and promote career development for local people through local resources because there is abundance of local natural resources, human resources and cultural resources.

National Culture Commission and the Department of Community Development should apply this research to study the feasibility of data collection of the local community in order to create a knowledge base and measure the potential of the village, community and culture. Then find ways to promote the indigenous knowledge and support development in rural villages. This will provide a status and indication of the villages and community weaknesses or strengths, what part will be developed and how it develops.

The Ministry of Education and the Ministry of Culture should apply the research process in education and the preservation and promotion of culture in the country. Create a learning process and the study the factors that can affect the culture of the country, resulting in conservation projects and culture in a systematic and consistent coordination between government agencies, private sector and communities, both regionally and nationally. Participation from all parties will strengthen the culture in the community and bring pride to the nation's cultural identity.

Suggestions for future research studies: Suggestions for future research studies should be supported and granted to include research topics of: Mahoree in Lao people's democratic republic, Cambodia and Thailand. Comparative study of Mahoree in other areas of Cambodia, Mahoree in the courts of Cambodia. Research study on creating Directory of Mahoree musicians in Cambodia and Thailand and extensive research on creating guidelines for the preservation and promotion of Mahoree in Thailand, Cambodia, Lao People's Democratic Republic.

\section{ACKNOWLEDGEMENT}

The researchers would like to thank the Office of the Higher Education Commission for support of the research funding for the academic year 2008.

\section{REFERENCES}

Chaichitsakun, P., 2002. Diffussion of thai musical culture: Case study of ampawa community, samut songkram province. Ramkhamhaeng University, Dissertation, Bangkok.

Chasuwan, S., 2006. Indigenous knowledge of thai music: Model of learning and knowledge diffusion of music families. Suan Sunandha Rajabhat University, Bangkok.

Chonpairot, M., 2008. Conservation and revitalization and development of cultural identity and traditions of the kula ethnic in isan. Mahasarakham Univesity, Dissertation, Maha Sarakham.

Kuntan, W., 1957. General knowledge about thai music: 29th Education exhibition, supplementary document. Education Supervisory Unit, Department of Teacher Education, Ministry of Education, Bangkok.

Phongphon, P., 2008. Kratu music: Lao people's democratic republic. Kasetsart University, Dissertation, Bangkok.

Sisantisuk, S., 2001. Study of society and culture: Concept, methodology and theory. Faculty of Humanities and Social Sciences, Prince of Songkla University.

Ueasaman, A. and E. Changes, 1994. Society and culture of villages along the munriver basin: Case study of the village of ban tum, tha tum district, surin province. Srinakharinwirot University, Maha Sarakham Campus, Dissertation, Maha Sarakham.

Wasi, P., 1994. Culture and development. Office of the Culture Commission, Kurusapa Press Ladprao, Bangkok.

Wongsuwan, K., 2006. Diffussion of thai music by indigenous philosophers in bansomdejchaopraya rajabhat university. Silpakorn University, Dissertation, Bangkok.

Zainal, M.R.M., S.A. Samad, A. Hussain and C.H. Azhari, 2009. Pitch and Timbre determination of the Angklung. Am. J. Applied Sci., 6: 24-29. DOI: 10.3844/ajassp.2009.24.29 